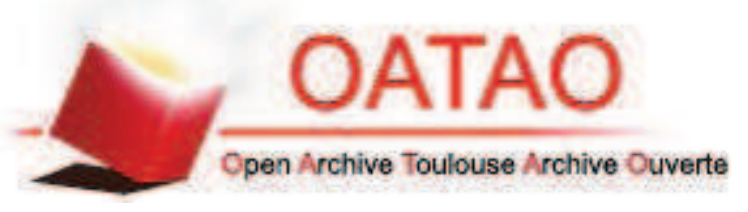

Open Archive TOULOUSE Archive Ouverte (OATAO)

OATAO is an open access repository that collects the work of Toulouse researchers and makes it freely available over the web where possible.

This is an author-deposited version published in : http://oatao.univ-toulouse.fr/ Eprints ID : 10262

To link to this article : DOI:10.1080/10255842.2011.592377

URL : http://dx.doi.org/10.1080/10255842.2011.592377

To cite this version : Le Roux, Mélanie and Magnaudet, Jacques Simulation of neutrophil motion and deformation: influence of rheology and flow configuration. (2011) Computer Methods in Biomechanics and Biomedical Engineering, vol. 14 ( $\mathrm{n}^{\circ} \mathrm{S} 1$ ). pp. 107-109. ISSN 1025-5842

Any correspondance concerning this service should be sent to the repository administrator: staff-oatao@,1istes-diff.inp-toulouse.fr 


\title{
Simulation of neutrophil motion and deformation: influence of rheology and flow configuration
}

\author{
M. Le Roux* and J. Magnaudet* \\ Institut de Mécanique des Fluides de Toulouse, Allée Camille Soula, 31400 Toulouse, France
}

Keywords: neutrophil; Navier-Stokes equations; volume of fluid technique; Oldroyd-B fluid

\section{Introduction}

The accumulation of neutrophils in pulmonary capillaries, and their low deformability may provoke the acute respiratory distress syndrome (Doerschuk 2001). A way to progress in the detection of this syndrome is to design a microfluidic device capable of detecting it. This is the final objective of the collaborative work that we currently carry out with experts in both biology and microfluidics. The specific aim of our team was to simulate the white blood cell behaviour in several flow configurations involved in the lung capillaries, which always implies a high degree of confinement because the actual capillary diameters are significantly smaller than the typical size of the neutrophils. Several models have been proposed to describe the rheology of white blood cells (Shirai 2008). The main objective of our work was to study the influence of the cell rheology on the displacement and deformation of the neutrophils within the capillaries. Basically, the questions to be addressed concern the influence of the core of the cell (which deforms only very slowly) on that of the viscosity and possible elasticity of the cytoplasm, and on that of the membrane that surrounds the cell and separates it from the outer plasma.

\section{Numerical methods and flow configurations}

So far, numerical simulations have been carried out in two dimensions (although our code is fully 3D), using a volume of fluid approach that allows us to follow the deformation of the neutrophil by identifying the interface between the cytoplasm and the surrounding plasma, thanks to a colour function. In the first step, we simply represent the cell as a Newtonian liquid drop with a cortical tension. In the second step, we take into account the influence of the core by including a non-deformable solid within the cytoplasm. This element was numerically implemented, thanks to an immersed boundary method (Peskin 2002). To improve this rough model, we then model the cytoplasm as a viscoelastic fluid corresponding to the
Oldroyd-B model. The associated constitutive equation that is known to often lead to numerical difficulties is solved explicitly, using the elastic-viscous-split-stress method to improve the stability of the model (Rajagopalan et al. 1990).

The final improvement of our description (not yet implemented) will consist in adding an elastic membrane around the cytoplasm to uncouple the outer and inner flows and to limit the cell area. In what follows, we show how the above first three steps of our model perform in two different flow configurations with low Reynolds number $(R e<1)$. We first discuss the cell behaviour in a numerical four-roll mill involving four separated streams for which the flow rate can be freely adjusted so as to obtain a central region with all possible linear flow fields, from pure strain to pure rotation, including of course the uniform shear case (Deschamps et al. 2009). We then consider a single tube with a contraction followed by an expansion, in which the dynamics of the extension and retraction of a single cell can be observed.

\section{Results and discussion}

The four-roll mill device may be seen as a numerical rheometer in which the response of the cell to any canonical linear flow can be studied in detail (Figure 1). In each simulation, we start with an initially circular cell located at the centre of the device; this position is stable under the Stokes flow conditions achieved in the computations.

In elongational flow configurations, the cell lengthens and slenderises, and we study the corresponding shape variations as a function of the various physical parameters (surface tension, Newtonian and polymeric viscosity of the cytoplasm).

Not surprisingly, the larger the capillary number, the larger the elongation of the cell. The presence of a rigid core $\left(r_{\text {core }} / r_{\text {cell }}=0.4\right)$ changes the final shape, especially for large deformations. For $\mathrm{Ca}=10^{3}$, the aspect ratio of the cell with and without the core is 0.03 and 0.076 ,

*Corresponding authors. Email: mleroux@imft.fr; magnau@imft.fr 


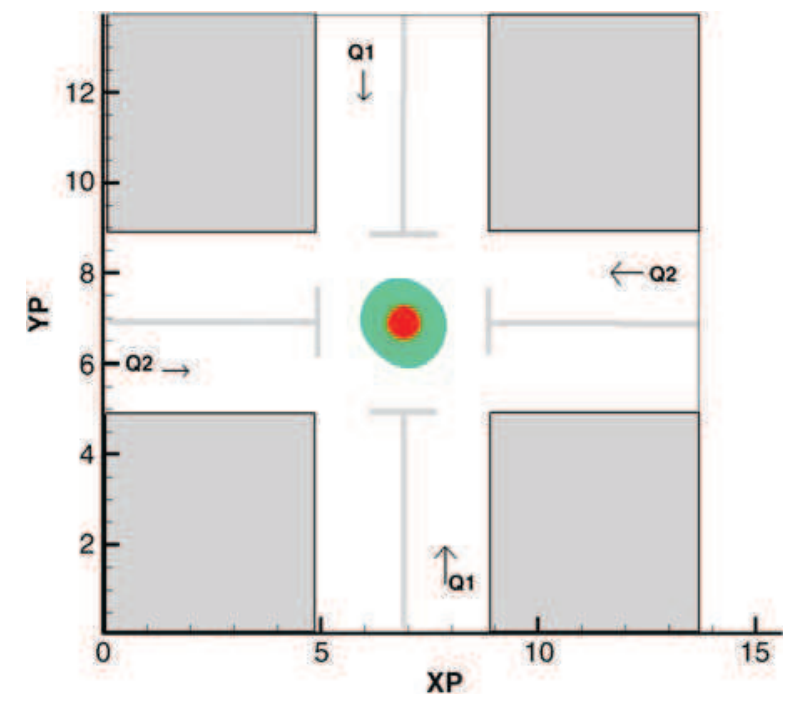

Figure 1. A tumbling cell in a shear flow in the four-roll-mill numerical device. The cell and the entrance of each channel have the same radius $\left(r_{\text {cell }} / r_{\text {in }}=1\right)$; the flow rates are such that $Q 1 / Q 2=0.7$. The physical parameters are such that $\mu_{\mathrm{d}} / \mu_{\mathrm{s}}=10^{2}, \operatorname{Re}=10^{-2}$ and $\mathrm{Ca}=10^{-9}$.

respectively. Similar numerical experiments were carried out with a simple shear flow to observe the lengthening and rotation of the cell. The flow and cell parameters are indicated in the caption of Figure 1. Under these conditions, the cell reaches a tumbling mode with $L_{\text {max }} / r_{\text {cell }}=1.265$. A noticeable difference with the purely elongational flow is that the presence of the core does not have any significant impact on the final shape of the cell.

Our second series of computations shows how a Newtonian drop with surface tension and with or without a solid core, passing through a 5:1 contraction followed by an expansion, deforms, elongates and then retracts when it enters the enlarged part of the capillary. In this simulation, the Reynolds number is fixed to 0.8 , the capillary number is varied from $4.4 \times 10^{-2}$ to $7.5 \times 10^{-1}$ and the viscosity ratio is varied from 0.31 to 3.22 to study the influence of both surface tension and viscosity on the time it takes to the drop to enter the contraction and achieve its maximum elongation. Our results compare well with those of Harvie et al. (2008), indicating that our numerical code performs properly for a Newtonian cell.

Figure 2 shows that for a given capillary number, the higher the viscosity ratio, the slower the cell enters the contraction. When a non-deformable core is added to the cell $\left(r_{\text {core }} / r_{\text {cell }}=0.23\right)$, the flow in the contraction is affected. Especially, the thickness of the liquid film that surrounds the cell becomes non-uniform due to the variation of the cell deformability in the neighbourhood of the core. However, as the core is non-deformable and small compared with the constriction radius, it does not affect the entrance time nor the velocity of the cell in the small part of the pipe. As can be seen in Figure 2, the presence of

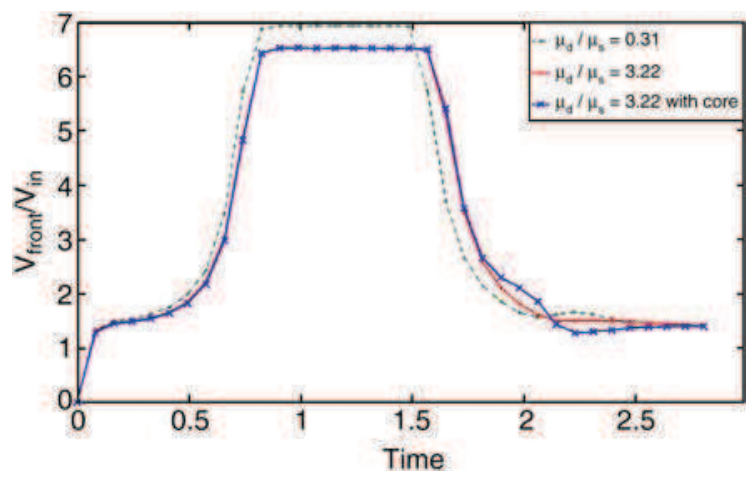

Figure 2. Temporal evolution of the drop front velocity in a 5:1 contraction. The cell radius is $80 \%$ of the radius of the contraction $\left(r_{\text {cell }} / r_{\text {in }}=0.8\right)$.

the core does not change the velocity in the constriction; in contrast, the velocity in the outlet region is significantly affected.

\section{Conclusions}

We develop a computational approach to study the motion and deformation of a neutrophil. Our work is still under progress and for the time being the rheology of the cell is crudely represented by a Newtonian or viscoelastic fluid, with or without a central solid core. Two different flow configurations were presented in which we varied to some extent three of the four physical parameters available in the model, namely the surface tension, the core-to-cell radius and the Newtonian viscosity, so as to determine their respective influence. Our results compare quantitatively well with those of available computations in the case of a Newtonian drop flowing in a contraction followed by an expansion. We are currently studying the influence of the non-Newtonian character of the cytoplasm by varying the polymeric viscosity; we are also investigating in detail the response of the cell to various linear flows in the four-roll mill configuration. Next, we will improve the representativity of the model by introducing an elastic membrane surrounding the cytoplasm.

\section{Acknowledgements}

We thank the French Agence Nationale de la Recherche for supporting this work, especially the PhD fellowship of M. Le Roux, under grant ANR-09-BLAN-0092-03 and CALMIP for providing the HPC resources under grant 2011-P1015.

\section{References}

Deschamps J, Kantsler V, Segre E, Steinberg V. 2009. Dynamics of a vesicle in general flow. Proc Natl Acad Sci USA. 106: $11444-11447$.

Doerschuk CM. 2001. Mechanisms of leukocyte sequestration in inflamed lungs. Microcirculation. 8:71-88. 
Harvie DJE, Cooper-White JJ, Davidson MR. 2008. Deformation of a viscoelastic droplet passing through a microfluidic contraction. J Non-Newton Fluid Mech. 155:67-79.

Peskin CS. 2002. The immersed boundary method. Acta Numer. 11:479-517.
Rajagopalan D, Armstrong RC, Brown RA. 1990. Finite-element methods for calculation of steady, viscoelastic flow using constitutive equations with Newtonian viscosity. J NonNewton Fluid Mech. 36:159-192.

Shirai A. 2008. Modeling neutrophil transport in pulmonary capillaries. Respir Physiol Neurobiol. 163:158-165. 